\title{
ASSOCIATION OF SMARTPHONE ADDICTION AND WRIST PAIN IN MEDICAL STUDENTS
}

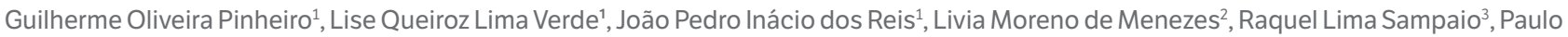
Goberlânio de BarrosSilva ${ }^{1}$, Jobson Lopes de Oliveira ${ }^{1,3, *}$

1.Centro Universitário Christus, Fortaleza (CE), Brazil. 2.Universidade de Fortaleza, Fortaleza (CE), Brazil. 3.Universidade Federal do Ceará, Fortaleza (CE), Brazil.

*Corresponding author: jobson.oliveira88@gmail.com

\section{BACKGROUND}

Smartphone is a popular device among young people. Many mobile devices users experience arthralgia, particularly in their wrist, but few studies were conducted to evaluate whether those who develop pain are smartphone addicts or not. The aim of this survey was to determine the prevalence of dependency of smartphones among medical students and to investigate the association between smartphone addiction and wrist pain.

\section{MATERIALS AND METHODS}

This study carried out from April 2020 to August 2020 to collect data from a population of university students from four schools of medicine in Fortaleza, Brazil, two of which are governmental universities and the other two are private universities. The survey was conducted by using a Google Forms that was sent via online communication to all medical students. The Google Form was adjusted to prevent submission of answers more than one time. Any participant who was not willing to answer could decline as per his or her discretion. The smartphone addiction scale-short version (SAS-SV) was used to divide participants into the smartphone addict group and non-addict group. Both groups completed the self-administered patient-rated wrist evaluation (PRWE) questionnaire, in which higher scores indicate worse function and more pain.

\section{RESULTS}

A total of 505 medical students were enrolled, 294 (58.2\%) were women. The mean age was $21.65 \pm 3.44$ years. The majority of participants were righthanded (91.1\%). According to the SAS-SV results, 235 (46.5\%) participants were considered to be smartphone addicts and 276 (54.7\%) used a smartphone for more than five hours daily. There was a significant association between smartphone addiction and high PRWE total score (15.81 $\pm 13.63 \mathrm{vs} .13 .43 \pm 12.86, p=0.004)$, high pain subscale $(12.70 \pm 10.26 \mathrm{vs} .10 .34 \pm 10.15$, $p=0.006)$ and high functional subscale $(9.71 \pm 6.22 \mathrm{vs} .9 .59 \pm 5.05, p=0.006)$. No differences were observed regarding wrist pain and sex, age or dominant hand.

\section{CONCLUSION:}

Our study found a significant association between overuse of smartphone and wrist pain. Further research is necessary to develop guidelines for wise use of mobile phones, in order to prevent such symptom. 